\title{
Simulação de um Vocoder Digital
}

\author{
Marco Antonio T. Pereira e Fernando Acatauassu G. Ferreira
}

\begin{abstract}
Este trabalho apresenta os métodos empregados para a simulação de um vocoder LPC-10 utillzando algoritmos de domlnio público, sendo que introduzimos algumas modificaçరes na declsăo sonoro/surdo que resultaram em sensivel melhoria na qualidade de voz sintetizada. Discutlmos o "soft ware" e o "hardware" utilizados para a simulaçăo, e finalizamos apresentando os resultados obtidos baseados em um teste de inteligibilidade para a voz sintética, também por nós desenvolvido.
\end{abstract}

\section{Introdução}

Este trabalho discute a simulação de um vocoder ("voice coder"), trabalhando à taxa de 2000 bit/s utilizando um sistema com barramento STD [1]. 0 vocoder simulado utiliza o método de Codificação por Predição Linear (LPC -"Linear Predictive Coding") [2] e a extração do período fundamental ("pitch") e decisão sonoro/surdo usando o algoritmo de Gold e Rabiner [3] e [4] com uma sofisticação, por nós introduzida, no que se refere à decisão sonoro/surdo.

Apresentamos a seguir o modelo utilizado (que inclui algoritmos modificados, mais eficientes), a forma como o mesmo foi simulado, e os resultados obtidos na simulação através da aplicação de um teste de percepção que criamos como uma ferramenta de auxilio para chegarmos a conclusōes mais reais.

Concluímos o trabalho com observações sobre perspectivas de melhoria na qualidade de voz utilizando o modelo explorado.

\section{Métodos Utilizados}

O modelo que examinamos, o LPC-10 (10 pólos), é um sistema que pode ser classificado como um Codificador Paramétrico ${ }^{1}$, ou seja, representa a

1. As desıgnaçס̃es Codlficador do Tipo Análise-Síntese e Codificador de Fonte săo também utilizadas como sinônimos de Codificador Paramétrico. Em particular, a expressăo Codificador de Fonte \& multas vezes empregada com um sentido bem mais amplo.

Os autores såo diretores da Kernel Informática Ltda, SIA Trecho 2, lote 1205, 71200, Brasnlia, DF. 
fala por parâmetros correspondentes a um modelo que define o mecanismo de sua produção. Estes parâmetros são transmitidos e serăo utilizados na recepção para reconstrução da mesma. Este modelo supõe independência entre a fonte de excitação e o sistema do filtro que reproduz o trato vocal humano. Assim, podemos analisar e sintetizar a função de transferência do trato vocal sem considerar o tipo de excitação que será utilizado. Este modelo é geralmente utilizado até uma taxa de transmissão de no máximo $4800 \mathrm{bit} / \mathrm{s}$. O LPC está descrito em detalhes em [2] e o seu diagrama em blocos simplificado, representativo do mecanismo de produção da fala, está mostrado na Fig. 1.

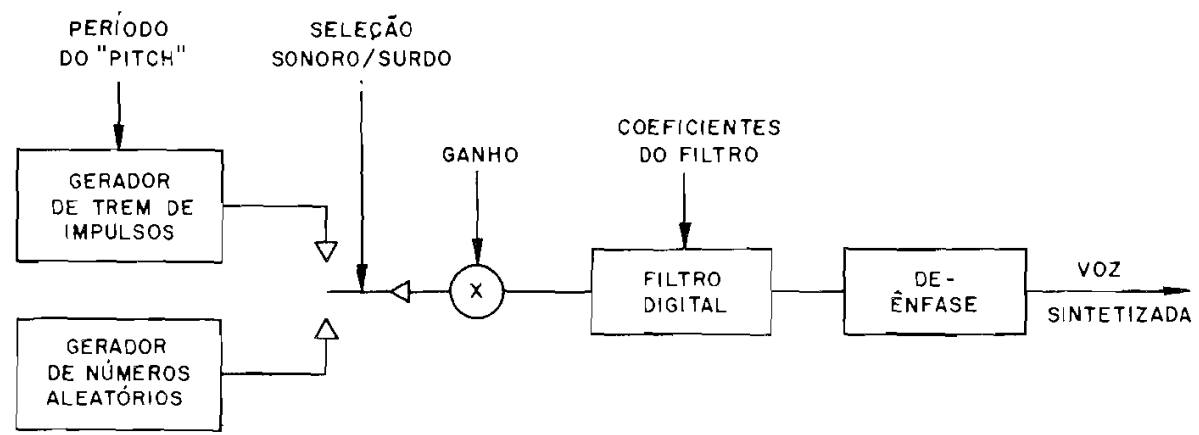

Figura 1. Modelo simplificado para produção da fala.

Conforme esta figura, existem dois tipos possiveis de excitação, ditas sonora e surda. O período fundamental estabelece o período da excitaçāo do gerador de trem de impulsos para excitações tipo sonora, e o gerador de números aleatórios simula a excitação tipo ruidosa dos sons fricativos e oclusivos. O tipo de excitação é selecionado pela chave. Existe um fator de ganho e o filtro digital variante no tempo responsável pelo modelameto da excitação que reproduzirá a fala. A de-ênfase compensa a pré-ênfase, introduzida na análise da voz a fim de compensar os efeitos do espectro do pulso glotal e radiação labial, que resultam em uma queda de cerca de $6 \mathrm{~dB} /$ oitava no espectro do sinal de voz.

$O$ conjunto de processos que resultam na extração dos parâmetros correspondentes aos coeficientes de predição e ao ganho $G$ está ilustrado na Fig. 2. Após a pré-ênfase, ocorre a extração de parâmetros via autocorrelação, que exige uma janela anterior (Hamming) para reduzir o efeito entre as amostras de janelas consecutivas no processo de análise, e também para limitação do intervalo de análise. Estas janelas, no nosso caso, tem a duração de $25 \mathrm{~ms}$ e não há superposição entre elas. Para chegar aos parâmetros temos de resolver um sistema de equaçóes, o que é feito utilizando o método de Durbin [2] e [5]. O parâmetro do ganho é extraído a partir dos coeficientes de prediçāo [2]. No caso deste valor estar abaixo de um determinado valor limite, temos um quadro de silêncio. Observe-se que a saída do último bloco 
na Fig. 2 é constituída pelos coeficientes de correlação parcial $k_{i}$ ( $i=1, \ldots$, P) e pelo ganho G. A obtenção desse conjunto de parâmetros é equivalente à obtenção dos coeficientes de predição e ganho [2].

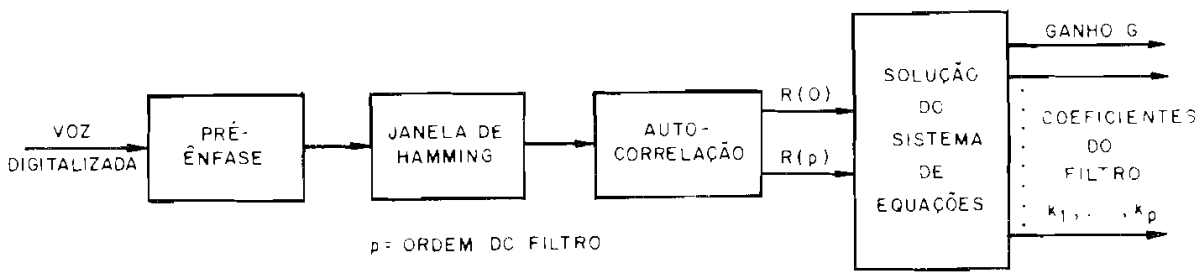

Figura 2. Extração dos coeficientes do filtro e do ganho.

O processo para extração do valor do período fundamental referente ao segmento analisado é iniciado com a aplicação do método de processamento paralelo proposto por Gold e Rabiner [3]. Ele se baseia em uma análise comparativa da amplitude de picos e vales do sinal de voz. São geradas seis medidas diferentes, das quais resultam o valor de duas variáveis que serão utilizadas na determinação do valor final do período fundamental: o período fundamental selecionado pelo aigoritmo para um dado quadro analisado e a nota atribuída a este período fundamental no processo de escolha. A nota é um valor ponderado gerado pelo próprio algoritmo de Gold e Rabiner. significando em última análise a probabilidade daquele valor de periodo fundamental escolhido estar correto.

A princípio a decisão sonoro/surdo estava embutida na própria extração do periodo fundamental. Um valor de período fundamental zero significa um quadro surdo. Porém, como desta forma a qualidade da voz reproduzida era bastante pobre, a decisão sonoro/surdo, a partir da idéia descrita em [6], foi sofisticada e passou a utilizar algumas outras variáveis. A decisão utiliza agora o valor do período fundamental e nota estabelecidos conforme descrito acima, a taxa de cruzamento de zero no quadro, o valor do ganho (G) já extraído, além do erro médio quadrático. A taxa de cruzamento de zero é o número de vezes que o sinal analógico de voz no quadro sob análise cruzou um valor de referência.

O cálculo do erro médio quadrático utiliza valores derivados da análise LPC. $\mathrm{O}$ erro médio quadrático $\tilde{\mathrm{E}}_{\mathrm{n}}$ é definido como

$$
\tilde{E}_{n}=\sum_{m=0}^{N-1} e^{2}(m)
$$


onde $N$ é o comprimento da janela $e$

$$
e_{n}^{(m)}=s_{n}^{(m)}-\hat{s}_{n}^{(m)}
$$

$\operatorname{com} s_{n}^{(m)}$ designando a m-ésima amostra na saída da janela de ordem $n$ e $\hat{s}_{r !}^{(m)}$ denotando a predição desta amostra. Representando por $E_{n}$ o valor mínimo, do erro médio quadrático $\widetilde{E}_{n}$, tem-se então [2]

$$
E_{n}=R_{n}(0)-\sum_{k=1}^{P} a_{k} R_{n}(k)
$$

onde os valores $\left\{a_{k}\right\}, k=1, \ldots, P$ são os coeficientes de predição; $P$ é a ordem do preditor (no caso, 10); e $R_{n}(k)$ são valores da autocorrelação para a janela considerada, ou seja

$$
R n(k)=\sum_{m=0}^{N-1-k} s_{n}^{(m)} s_{n}^{(m+k)}
$$

Ao invés de trabalhar com $E_{n}$ é conveniente definir um erro normalizado En dado por

$$
E_{n}=\frac{E_{n}}{R_{n}(0)}
$$

Esta normalização assegura que $0<\bar{E}_{n}<1$ e permite trabalhar em ponto fixo. Na implementação prática, em matemática de ponto fixo, poderíamos incorrer em problemas de precisão numérica não fosse esta precaução.

De posse destas variáveis, o algoritmo de decisão sonoro/surdo estabelece o período fundamental eleito, o qual ou é o valor de período fundamental originalmente extraído pelo algoritmo de Gold e Rabiner, evidenciando um quadro sonoro, ou é zero, evidenciando um quadro surdo. O processo de decisão utiliza os valores das variáveis citadas, que devem se encaixar em faixas de valores predeterminados para as várias tomadas de decisão. Os valores limites destas faixas foram determinados através de experimentação. O fluxograma do algoritmo para tomada de decisão sonoro/surdo está na Fig. 3. Este algoritmo, por nós desenvolvido, se aplicou muito bem às situaçōes consideradas. A comparação entre a opção tomada pelo algoritmo com aquela que resultaria de uma inspeção visual do quadro analisado, indica uma précisão de decisão sonoro/surdo de $86 \%$. Para fins de levantamento desta estatística foram efetuadas 50 comparaçōes. 


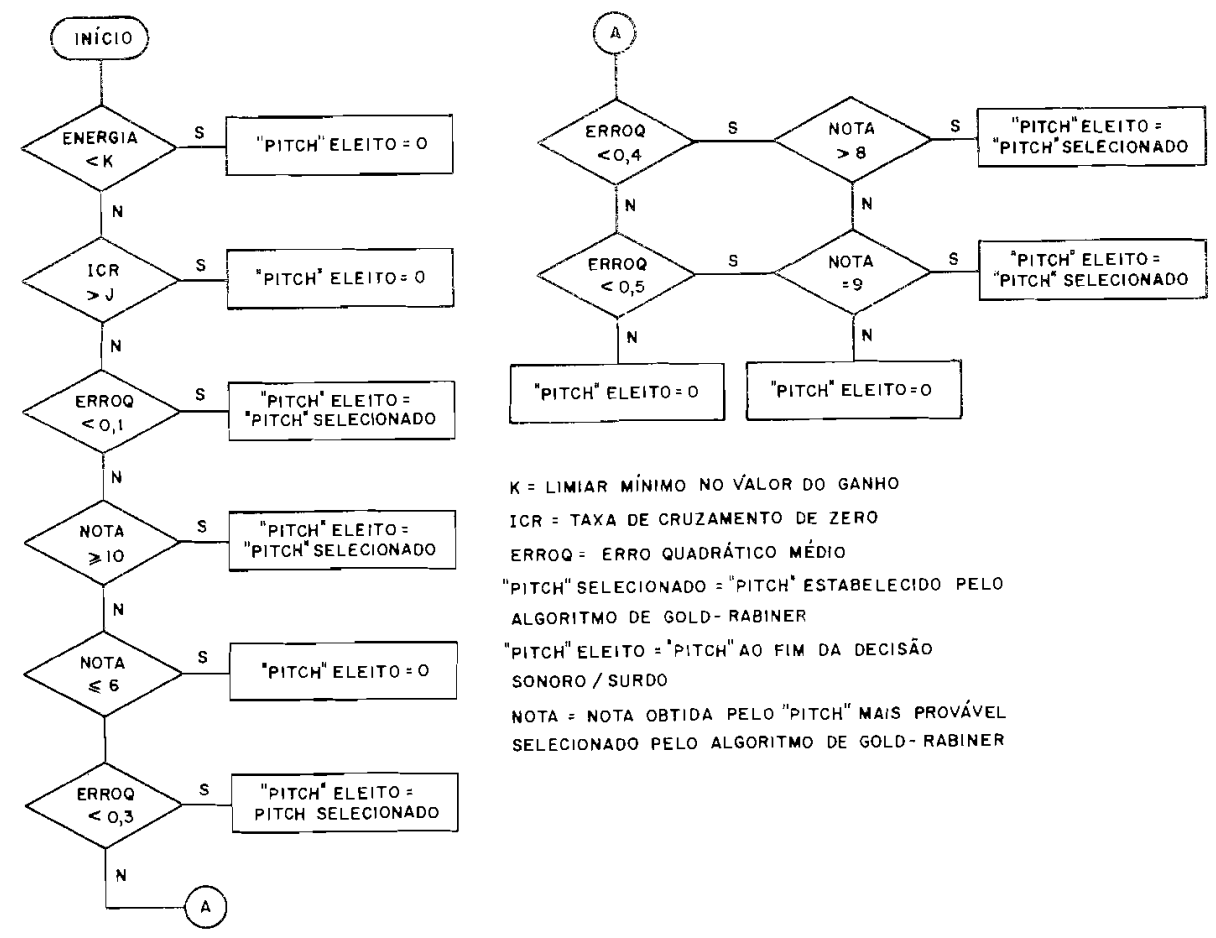

Figura 3. Fluxo para tomada de decisão sonoro/surdo.

Mas este ainda não é o valor utilizado como periodo fundamental final para o processo de síntese. Existe ainda um algoritmo de suavização para a retirada de erros grosseiros. Ele compara o valor encontrado para o período fundamental com o valor passado e dois adiantados, evitando estes erros. Utilizando os valores do período fundamental destes três quadros e do quadro atual, se em meio a quadros surdos o algoritmo encontra um quadro sonoro, ele automaticamente o transforma em surdo, e vice-versa. Da mesma forma, se no início ou finalização de quadros é detetado um quadro sonoro, ele também é automaticamente transformado em surdo. Desse modo, os erros grosseiros evitados pelo algoritmo de suavização são:

(i) deteção isolada de quadros sonoros ou surdos;

(ii) estimativa de valores de período fundamental diferentes de zero no início ou fim de regiōes sonoras.

O diagrama em blocos de todo o processo, a partir das amostras de voz até a obtenção do período fundamental final, está na Fig. 4. 


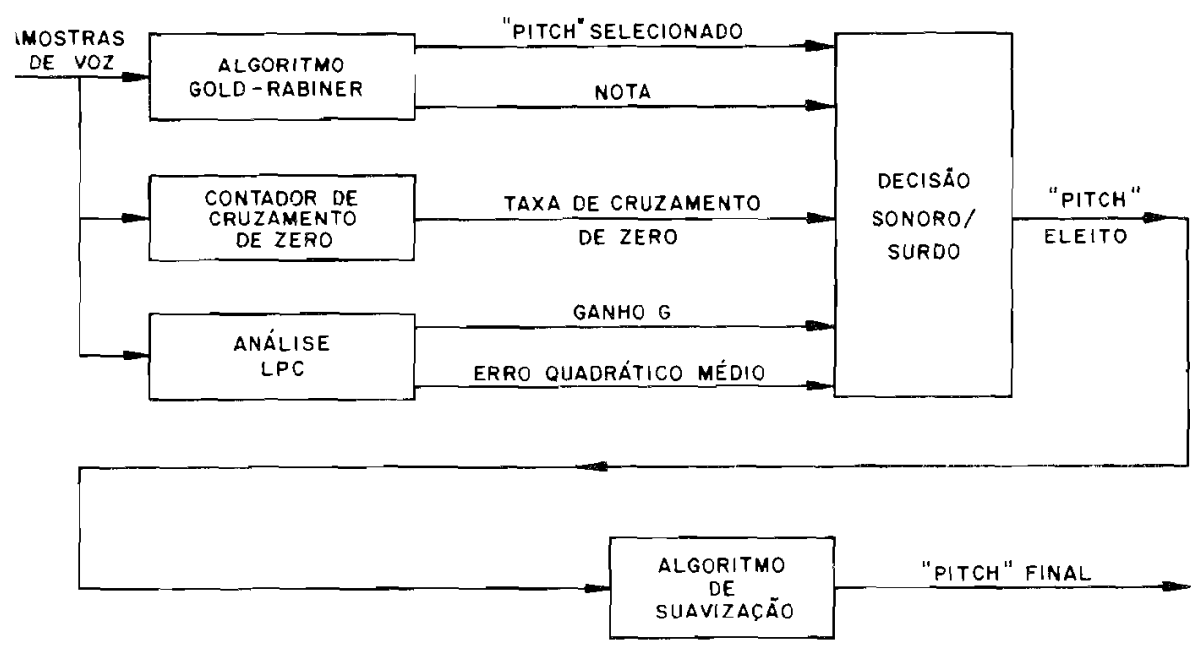

Figura 4. Diagrama em blocos para o processo de extração do "pitch".

Após a extração de todos os parâmetros, eles são codificados da seguinte forma, segundo exigência do sintetizador utilizado [7]: energia, 4 bits; período fundamental, 6 bits, $k_{1}$ e $k_{2}, 5$ bits cada; $k_{3}, k_{4}, k_{5}, k_{6} k_{7}, 4$ bits cada; $k_{8}, k_{9}$ e $k_{10}, 3$ bits cada; além de 1 bit para indicar repetição de quadro que não foi utilizado. Como a duração da janela utilizada é de $25 \mathrm{~ms}$ temos uma taxa de $40 \mathrm{~Hz} \times 50 \mathrm{bits}=2000 \mathrm{bit} / \mathrm{s}$.

\section{A Simulação}

Para efetuarmos a simulação deste conjunto de algoritmos que resultam em um vocoder, utilizamos um microcomputador baseado no microprocessador 8088 da Intel em um barramento STD. A simulação tem como objetivo fundamental assegurar o funcionamento de cada sub-sistema dentro de uma dada realidade que será a esperada no equipamento final, bem como a integração dos vários sub-sistemas. Entendemos aqui por sub-sistema cada um dos vários módulos de "software". Na simulação, para a observação de desempenho do modelo, podemos criar condiçōes, alterar valores de variáveis e provocar situações de funcionamento nos extremos desejados. Por exemplo, os valores limites para as variáveis utilizadas na decisão sonoro/surdo foram determinados de maneira iterativa nesta fase de simulação, com a ajuda do "hardware" e "software" descritos a seguir.

Para que o microcomputador pudesse obter amostras de voz para trabalhar, e para que depois fosse possivel ouvir os resultados, foi desenvolvida uma placa A/D/A (analógico/digital/analógico). Esta placa interage com o sistema microcomputador através do barramento STD, ocupando um conector livre 
do gabinete da máquina. Esta placa efetua três funções básicas: digitaliza o sinal analógico da voz; reconstrói a voz novamente a partir de voz digitalizada; e sintetiza a voz a partir dos parâmetros extraídos na análise LPC-10.

Para a primeira funçāo, a placa conta com um conversor analógico-digital de 12 bits e filtro "anti-aliasing" apropriado. As amostras de voz quantizadas em 12 bits que representam a frase falada são imediatamente transferidas para o sistema que se encarrega de abrir um arquivo e armazená-las. A memória de massa onde são armazenados estes arquivos é um disco rígido (Winchester) com capacidade de 10 Mbytes. Com isto, não enfrentamos grandes problemas de limitação de área de armazenagem para os arquivos de coleta de voz, que são geralmente bastante extensos, se comparados ao seu par sintetizado. Apenas é preciso ter um mínimo de critério no uso da memória e apagar arquivos já fora de uso. A freqüencia de amostragem é de $8 \mathrm{kHz}$.

Para reprodução de frases que foram apenas digitalizadas, a placa contém um conversor digital-analógico de 12 bits, seguido de filtro de reconstrução. Os arquivos que foram armazenados na memória de massa, compostos por amostras de 12 bits, podem ser redirecionados para reprodução novamente. Isto é importante para observação da gravação feita, bem como para comparar mais tarde com frases sintetizadas, realmente.

Para a execução da terceira função, a síntese da voz a partir de parâmetros LPC-10, a placa possui um Processador de Síntese de Voz da Texas Instruments, o TMS5220 [7]. Este é um componente dedicado, que implementa o filtro digital variante no tempo que simula o trato vocal, filtro este que é excitado ou pelo trem de impulsos ou pelo gerador de números aleatórios, dependendo do tipo de som ser sonoro ou surdo (ver Fig.1) A diferença com relação a esta figura é que o 5220 não realiza a pós-enfase, além de já conter o conversor D/A e um amplificador. Tornou-se então necessário implementar externamente ao 5220 a de-ênfase, analogicamente, porque o sinal entregue pelo 5220 já passou pelo D/A. Acrescentamos outro amplificador ao sinal de saída para termos um controle efetivo do volume da voz reproduzida. Este amplificador também é utilizado na reprodução da fala via D/A. Existe uma chave que possibilita direcionar uma das duas saídas para a reprodução.

Para a entrada da voz e a audição da mesma, utilizamos um monołone semelhante ao monofone de um telefone comum, mas com suas cápsulas trocadas por cápsulas dinâmicas. Toda entrada de sinal e posterior audição da voz, comprimida ou não, é feita via o monofone. A Fig. 5 ilustra a placa A/D/A sob a forma de diagrama em blocos. 


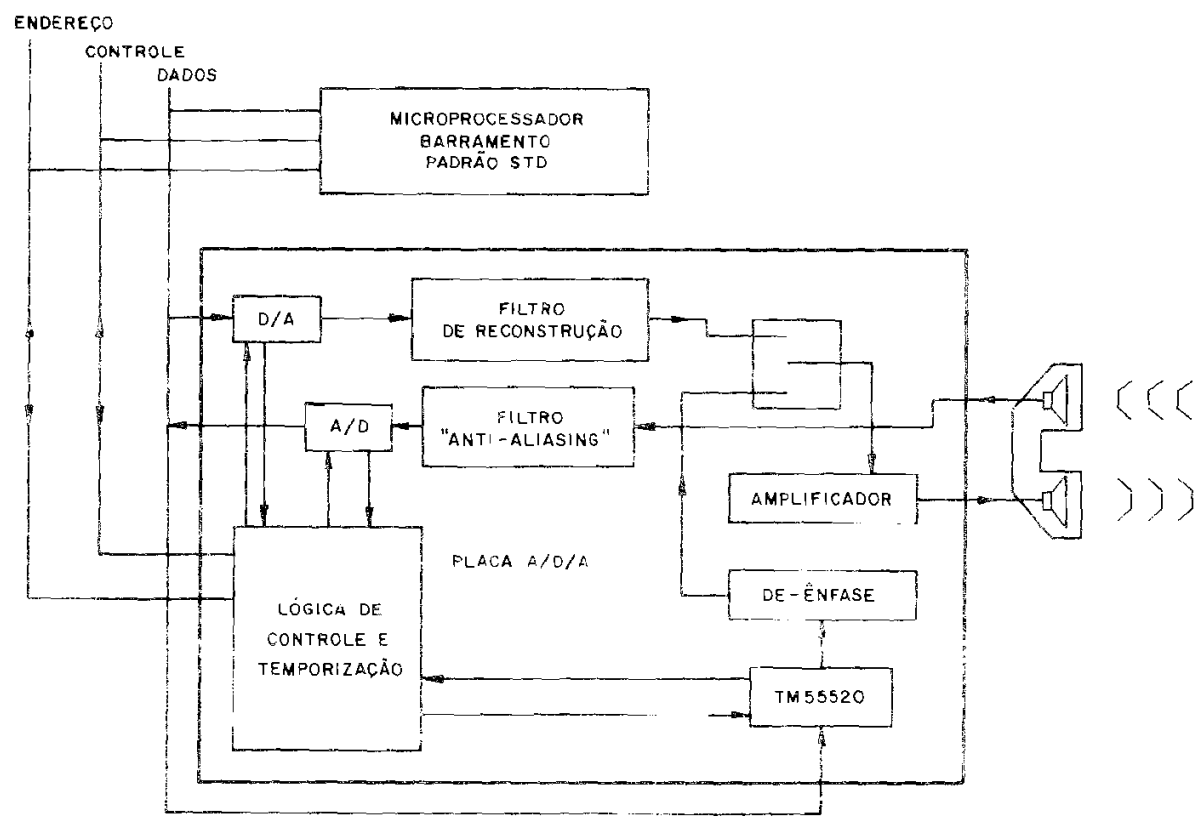

Figura 5. O sistema de simulação.

Em termos de "soltware", existem dois móaulos básicos: a parte de controle do sistema, e o "software" encarregado efetivamente de promover a extração dos paràmetros na análise LPC.

O "software" de controle foi escrito em "assembler" do 8088 e sua função principal é de coordenação. É ele que abre os arquivos para a coleta das amostras de voz e que os direciona para â reprodução via D/A. Este "software" pode direcionar para a saida um arquivo composto por parâmeiros LPC-10, que serāo reproduzidos pelo circuito integrado dedicado 5220. O usuário interage com a máquina através deste módulo. O programa após carregado coloca na tela um menu que oferece as seguintes opcóes disponivais: coleta de voz (C); reprodução via D/A (F); reprodução via 52220 (T); Ctrl C-retoma ao sisterna operacionai.

A partir de uma das três primelras opgoes, "sortware" pergunta o nome

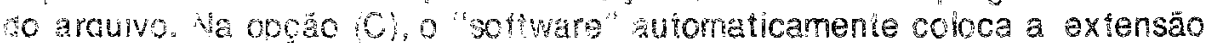
Abo ao nome ascohido oara o arcuvo ser aberto. Ao usermos a opçäo Fi, "sotware" jergunta a nome do arcuivo .ABD a ser poteado para - S/A. No caso da opço (T), o arruvo que é gerado após a analise terá autománcanente a sxtensão. The sctescida ao nome originamente escothido. sera reado para sintese no 2220 
Toda a parte de programação referente à análise da voz que resulta nos parâmetros LPC-10, ou seja, nos coeficientes de predição, no ganho e no valor do período fundamental, foi escrita em Turbo Pascal. Ao invocarmos - programa análise, ele pergunta qual o arquivo a ser analisado, que será um arquivo. $A B D$ criado através da opção $(C)$ do programa de controle. A análise consome bastante tempo de execução, porque são executados todos os algoritmos já descritos anteriormente. Este tempo gasto na análise é - limitador prático do tamanho dos arquivos de voz coletados, e não a nemória de massa, o disco rígido. Se a frase gravada ultrapassar os 30 segundos de duração, a análise já começa a tomar horas de processamento. Ao fim, temos o arquivo.TMS, jấ formatado de acordo com as exigências do TMS5220, pronto para ser utilizado pela opção (T).

Como o Pascal é uma linguagem estruturada, de fácil compreensăo, e como o programa é bem documentado, se torna bastante simples promover alteragóes nos algoritmos utilizados em todo o precesso de anáíise. No inicio do programa, onde todas as variáveís, limiares, constantes, etc, são definidos, existem comentários incicando o que é cada um destes elementos, de acordo com os algoritmos. Alterar qualquer um deles para promover experimentos, se trała simplesmente de alterar o valor atribuido à variável, ou iimiar etc, conforme o desejado.

Na verdade, sendo o Pascal uma linguagem estruturada, mesmo modificações de módulos de programa, ou seja, aiterações nos algoritmos, são razoavelmente fáceis de serem efetuadas para quem possui alguma prática com a inguagem.

\section{Resultados da Simulação}

Como a percepção auditiva é bestante subjetiva, afirmar que uma mudança em alguma parte dos algoritmos realmente resultou em meihoria năo é imedia10. Para avaliar as mudanças introduzidas, elaboranos um teste de percepção que pode ser aplicado sempre que conveniente. O teste é de multipla escolha, e o participante, após ouvir uma palavra, tem que escoiher entre três opçöes ascritas no papel a sua frente. Tanto a filosolia utilizada na constuçăo smo a exemplo da aplicaça de um seste se encontram no Apencics A.

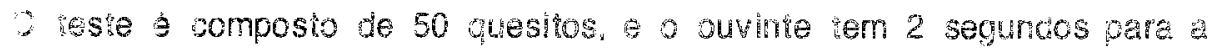
ża tomada de decisão antes he ouvir o póxmo conjunto de palavias. Como locutores, utlizamos duas vozes masculinas a duas vozes femininas "ntercaladas aleatoriamente, e inclusive com diferenças de solaque. 0 audito. "io rol composto por 29 pessoas, de diferentes ilpos de atividades e dierentes 
níveis sociais. Repare que neste teste não há informação contextual. Apenas a informação existente em uma palavra isolada é usada na tomada de decisão pela resposta escolhida. Com isto, se torna mais fácil observar o tipo de som que o sistema está tendo dificuldade de tratar e reproduzir, para assim, se possivel, aperfeiçoar o detalhe em questão.

O resultado da aplicação do teste no modelo análise/síntese como está atualmente alcançou $78 \%$ de acerto. $O$ mesmo teste aplicado a outra platéia, mas sem nenhum processo de compressão, alcançou $95 \%$ de acerto. Considerando que muitas das partes não entendidas em uma conversação normal são deduzidas a partir do contexto da conversação, não é de se acreditar que problemas sérios de compreensão surjam em uma aplicação prática do sistema vocoder conforme descrito. No caso em questão, o teste tem como finalidade somente a avaliação da inteligibilidade do sinal reproduzido. Também utilizamos recursos de equipamentos de teste e medição para observação de resultados, mas só foi possivel concluir sobre a real melhoria ou não de mudanças mais sutis nos algoritmos, a partir da aplicação do teste. De posse dos levantamentos feitos a partir dos resultados dos testes, observamos fatos bastante úteis para pesquisas futuras.

Considerando o universo de 50 palavras sintetizadas utilizadas no teste, a Fig. 6 mostra um gráfico de percentual de acerto dentro do total de palavras que compõem o teste. A partir destes resultados, concluímos que ocorreram erros localizados, cujas causas devem ser estudadas com mais profundidade.

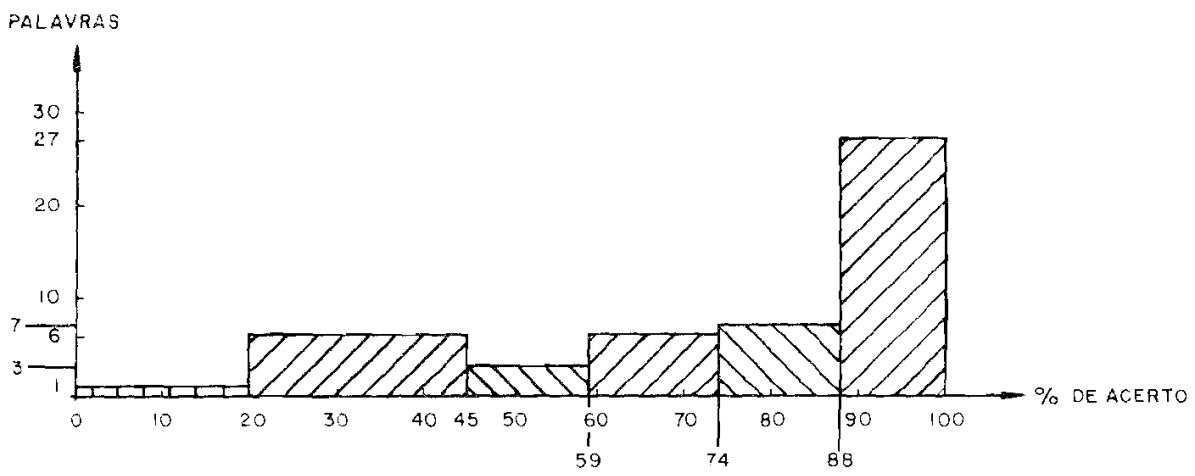

Figura 6. Distribuição percentual do acerto pelo total de palavras.

Conforme dito, utilizamos quatro vozes para nossas gravações, duas masculinas e duas femininas. A distribuição por acerto por locutor está na Fig. 7. Apesar da voz feminina ter mostrado melhor rendimento, podemos dizer que a máquina está bem ajustada, porque a diferença percentual entre os dois tipos de voz foi pequena. 


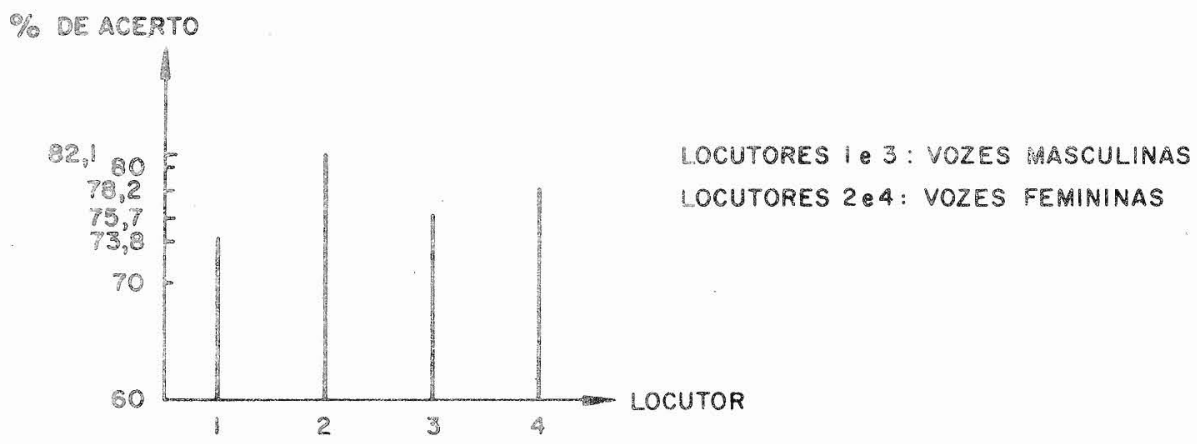

Figura 7. Distribuição percentual do acerto por locutor.

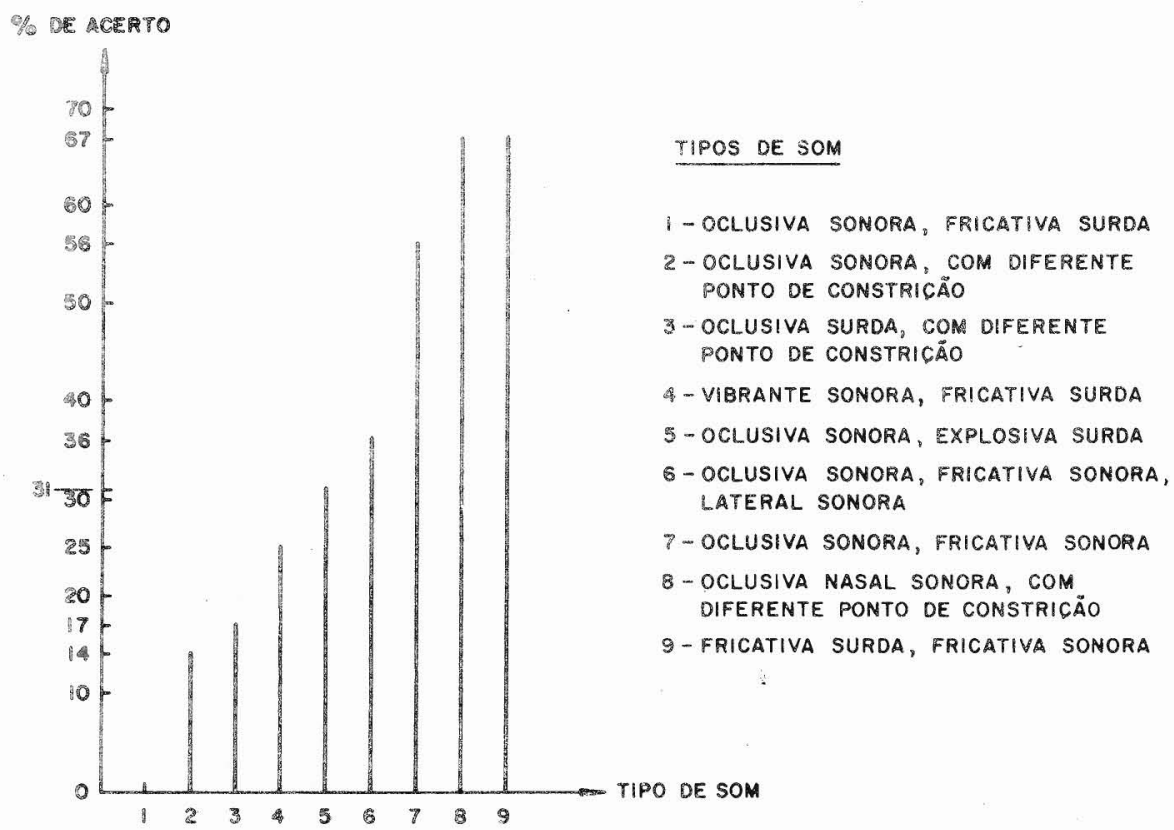

Figura 8. Distribuição percentual do acerto para alguns tipos de sons sintetizados.

A Fig. alguns tipos de sons sintetizados. A figura não cobre uma comparação entre todos os tipos de sons existentes, mas os que a principio se mostraram mais problenálicos de serem discernidos. A observação do gráfico demonstra grande dîliculdade de identificaçäo entre sons oclusivos surdos (cato, tato) diferenciados apenas pelo ponto de constrição do fonema, entre sons oclusi- 
vos sonoros (bica, dica) também diferenciados apenas pelo ponto de constrição do fonema, e em particular entre sons oclusivos sonoros e fricativos surdos (finco, som). Estudos mais profundos devem ser feitos para melhorar a reprodução e conseqüente identificação destes sons. Sons fricativos sonoros (zinco, juta) ou surdos foram bem diferenciados, bem como oclusivos nasais sonoros (neta, meta) diferenciados pelo ponto de constrição do fonema. Os demais encontraram notas razoáveis. Deve ser lembrado que estes percentuais são cálculos ajustados para os efeitos do contexto, conforme mencionado no Apêndice A.

$\mathrm{Na}$ verdade, para um resultado ainda mais consistente deste teste, seria necessário compor mais platéias, com elementos de atividades e niveis culturais os mais diferenciados possíveis, para obtenção de médias mais realistas. Observamos que elementos com melhor nível cultural, com maior vocabulário, obtêm um índice de acerto mais elevado. Da mesma forma, talvez fosse útil oferecer uma quantia em dinheiro pela participação no teste, para podermos de certa forma nivelar a boa vontade da platéia, porque observamos que o índice de acerto está relacionado também com o estado de espírito do ouvinte no momento da aplicação do teste. Por exemplo, o conjunto de palavras gingar, vingar, xingar, gerou $54 \%$ de acerto. Já o conjunto chá, já, vá, gerou $89 \%$ de acerto (cálculos feitos conforme indicado no Apêndice A). Ambas as questões são compostas por fricativos, diferindo entre som surdo ou sonoro. A diferença sensível no percentual de acerto deve ser imputada a razões subjetivas, como, por exemplo, o auditório utilizado não usar com freqüência palavras pertencentes ao primeiro conjunto.

O teste de avaliação é um ponto que merece estudos futuros mais profundos, pela sua vital importância para aprimoramento dos algoritmos.

\section{Conclusões}

Visando à construção de um vocoder, a simulação digital dos algoritmos envolvidos, apresentada neste trabalho, foi fundamental para assegurar 0 sucesso do empreendimento. Graças à experimentação de todas as condições esperadas, foi possível tirar conclusões e chegar a resultados de fundamental importância para chegarmos ao que consideramos uma boa qualidade de voz. Principalmente, a elaboração do algoritmo para decisão sonoro/surdo tirou grande proveito das facilidades de simulação. Inclusive, o equipamento final fará uso de um processador digital de sinais para efetuar a análise em tempo real, que trabalha em ponto fixo. Na simulação, foi também possível levar em consideração este detalhe, para avaliação de problemas de precisão numérica no ambiente futuro. 
O teste de inteligibilidade demonstrou ser uma ferramenta de grande importäncia para a pesquisa de soluçōes otimizadas. Sua estruturação, modo de aplicação, formação de platéias, etc, deveriam ser material. para pesquisas posteriores de pessoas com formação específica em fonética e fonologia, visando à elaboraçāo de um teste mais efetivo e preciso. No momento, não é de nosso conhecimento nenhum estudo desse tipo feito no Brasil.

Os resultados finais obtidos foram bastante satisfatórios, conforme ficou evidenciado pelo percentual de acerto obtido na aplicação do teste de inteligibilidade, apesar deste não ser ideal e ter sido aplicado a poucas platéias.

Baseado no percentual de acerto obtido como resultado da aplicação do teste de inteligibilidade, e mantendo a taxa de transmissão baixa como a alcançada, não acreditamos que grandes melhorias possam ser realizadas tentando explorar o modelo LPC tradicional. Algum progresso deve ser possível aperfeiçoando ainda mais os métodos de extração de período fundamental e decisão sonoro/surdo, mas um novo patamar de qualidade só poderá ser alcançado como resultado da criação de um novo modelo, um nova forma de atacar o problema, pelo menos a taxas não excedendo os $2400 \mathrm{bit} / \mathrm{s}$.

\section{Apêndice A}

Descrição do Teste de Inteligibilidade

Antes do advento das técnicas de codificação de voz, medir sua inteligibilidade era relativamente simples. Ruído, restrições na largura de faixa e limitações de potência eram as causas principais da degradação do sinal. Entretanto, o processamento digital de voz impõe suas formas de distorção próprias no sinal de voz. Em particular, técnicas que minimizam a largura requerida ao canal distorcem o sinal ainda mais. A complexidade destas distorções torna quase impossível predizer seus efeitos na inteligibilidade, a partir de medidas físicas feitas no sinal de voz processado. Assim é ainda necessário usar pessoas para este fim.

$\mathrm{Na}$ maior parte da interação verbal entre pessoas, existe mais de uma fonte de informação para se chegar ao conteúdo da mensagem: existe o estímulo da informação, isto é, a informação contida num segmento crítico da voz, e existe também muita informação dita contextual, ou informação contida nas circunstâncias da interação verbal. Estes fatores contextuais influenciam na percepção de fonemas, sílabas e outros elementos que compõem a conversação. O ambiente no qual ocorre a conversação (aviação, por exemplo) e a situação(aterrissagem, por exemplo) são informações que levam no seu contexto pistas para a compreensão da conversação em si. 
independentemente da importância do estímulo e coniexto, a inteligibilidade é determinada pela habilidade do ouvinte em assimilar a informação destas fontes. Corno a intuição sugere, a informação contextual é muito importante numa conversação, mas indivíduos diferem na sua capacidade de usar essa informação. Diferem mais do que na capacidade de usar outras caracteristicas das quais a inteligibilidade depende. $E$ este é um grande problema auando se pretende medir e controlar a inteligibilidade na somunicação faiada, : portanto de voz processada por técnicas de processamento digital.

Uma maneira razoável de controlar o nível de estímulo contido na informação é controlá-lo através da razão sinal-ruído na comunicação. Mas controlar a informação contextual já não é tão fácil. Informação contextual pode ser melhor definida como a totalidade de fatores, veroais e extra-verbais, que influenciam na probabilidade da ocorrência de um evento elementar na fala [8], [9], e daí a grande dificuldade de exercer um controle efetivo sobre eventos ião aleatórios. Em um teste, qual a quantidade de informaçăo contextual que deveria ser dada em um dado texto? O ideal seria dar a mesma quantidade que o ambiente, ou o meio no qual o equipamento será usado dará. Mas isto é praticamente impossivel de se jaber, mais ainda que um determinado equipamento pode se usado em situações as mais diversas. Assim, apesar de não reproduzir a condição real, a forma mais legítima de avaliar inteligibilidade em um sistema é usar modelos sem informação contextual. Mas mesmo isto é difícil, porque os ouvintes, ou pior ainda; apenas alguns dos ouvintes, sempre conseguem reduzir a incerteza do teste, através de associações entre palavras, diferenças no vocabulário mais usual entre os componentes da platéia e outros motivos.

Testes de múltipla escolha se prestam bə̉m para reduzir a quantidade de informação contextual em um teste. Uutro problema é a escolha do conteúdo do teste e como este será organizado. O processo de escolha de palavras e sua distribuição dentro do teste é essencialmente o mesmo que é usado por educadores para eliminar (ou recuzir) o efeito da escolha aleatória da resposta nos resultados de testes de múltipla escolha. Para pelo menos minimizar este efeito, a incerteza das deduções a priori tem que ser maximizada, ou seja, a contribuição de fatores contextuais tem que se reduzida. A fórmula que se segue é utilizada para dar resultados de testes considerando este problema, o que conduziria então a resultados mais reais. Supondo que todos os ítens são respondidos, tem-se de [10] que

$$
P_{c}=\frac{\frac{P_{r}-P_{W}}{n-!}}{T}
$$

onde $\mathrm{P}_{C}$ é a percentagem de acerto, ajustada para os efeitos do contexto, $P_{P}$ é o número de respostas corretas, $P_{W}$ é o número de respostas erradas, 
n é o numero de escolhas em cada fiem e $T$ é o número total de itens do teste.

Esta iórmula permite, por exemplo, uma comparacão significativa entre resultados de testes com tamanhos diferentes. Entretanto, a validade do resultado parte de duas premissas. A primeira é que os conjuntos de opções de respostas são compostos por unidades iguaimente atraentes. Por exemplo, um conjunto de respostas como gato, pato, caco, abacaxi afetaria a validade do resultado. A segunda premissa é que a resposta do ouvinte a um quesito depende de uma única decisão discriminativa. Quando o estímulo da incerezeza G confinado a um único fonema ou detalhe para a correta compreensão, a fórmula funciona bem.

Quando da apresentação do tesie à platẻia, outra pergunta que surge é quanto ao tempo indicado para os ouvintes tomarem a decisão da resposta. nos ítens do teste de múitipla escolha. Em testes deste tipo, feitos para a língua inglesa, o tempo ótimo para responder cada ítem está entre 1,5 a 4 segundos, aproximadamente.

A variação dos tipos de palavras no universo que compõe o teste também é fator a considerar. Se obtemos um certo resultado para um teste e depois aumentamos a variedade de tipos de sons cobertos pelo teste, sem melhorarmos a qualidade do som reproduzido, é previsivel uma queda no percentual de acertos.

É recomendåvel no teste de equipamentos que reproduzam a voz de alguma forma, o uso de mais de um locutor durante as gravaçōes. O ideal seria dispor de tantos locutores quantos são os ouvintes. Quanto ao número de ouvintes, experiências anteriores indicam que 8 a 10 ouvintes constituem uma platéia razoável para um dado leste, particularmente se são pessoas conscientes e com boa vontade, para que a consistência nos resultados possa ser mantida. Um pouco mais complicado é a escolha do número de opçóes de respostas dadas ao ouvinte. O DRT (Diagnostic Rhyme Test), por exemplo, permite a escolha entre duas opçóes, e 0 MRT (Modified Rhyme Test) entre sais [10].

Alén do número de respostas, a escolha apropriada de opçoes cieve considerar as características fonéticas a serem analisadas. Com isto, um estudo dos resultados colhidos evidenciará qual caracieristica sonora os algoritmos estão tendo dificuldades de reproduzir. As caracteristicas principais que consideramos são as seguintes: sons sonoros, sons surdos, sons nasais, sons orais, sons fricativos, sons oclusivos, sons laterais e sons vibrantes. No nosso teste, escolhemos somente palavras com estas caracteristicas, que são aqueias observadas de modo mais marcante na nossa língua. 
Também devem ser considerados a natureza e o volume do ruído de fundo durante a aplicação do teste. Assumimos o ruído ambiente normal, como ar condicionado, telefone, etc, como o ruído de fundo presente no recinto de aplicação do teste.

O teste que propomos elimina ao máximo a informação contextual, usando palavras fora de frases e o método de múltipla escolha. O tempo dado para que seja escolhida a resposta a cada ítem é de 2 segundos, e são três as opções de resposta para cada um deles. O teste é composto por 50 perguntas.

A seguir, a título de ilustração, apresentamos um teste completo, na forma em que é apresentado à platéia. O campo Teste Aplicado se refere ao tipo de teste que estamos aplicando: se voz simplesmente reproduzida ou digitalizada e comprimida.

\section{Teste de Identificação de Fonemas}

Ouvinte:

Data:

Teste Aplicado:

$\begin{array}{rlll}\text { 1) } & \text { paca } & \text { vaca } & \text { faca } \\ 2) & \text { mico } & \text { bico } & \text { pico } \\ 3) & \text { gato } & \text { tato } & \text { cato } \\ 4) & \text { seus } & \text { deus } & \text { zeus } \\ 5) & \text { grama } & \text { trama } & \text { drama } \\ 6) & \text { gingar } & \text { vingar } & \text { xingar } \\ 7) & \text { feio } & \text { veio } & \text { meio } \\ 8) & \text { vanda } & \text { panda } & \text { banda } \\ 9) & \text { gosta } & \text { posta } & \text { costa } \\ 10) & \text { finco } & \text { cinco } & \text { zinco } \\ 11) & \text { doca } & \text { foca } & \text { toca } \\ 12) & \text { chá } & \text { já } & \text { vá } \\ 13) & \text { vala } & \text { mala } & \text { bala } \\ 14) & \text { fada } & \text { nada } & \text { dada } \\ 15) & \text { beta } & \text { meta } & \text { teta } \\ 16) & \text { disso } & \text { viço } & \text { nisso } \\ 17) & \text { marca } & \text { barca } & \text { parca } \\ 18) & \text { dona } & \text { tona } & \text { nona } \\ 19) & \text { vingo } & \text { bingo } & \text { xingo } \\ 20) & \text { parda } & \text { sarda } & \text { farda } \\ 21) & \text { vê-lo } & \text { sêlo } & \text { pêlo } \\ 22) & \text { adaga } & \text { apaga } & \text { afaga } \\ 23) & \text { adora } & \text { arvora } & \text { arbora } \\ 24) & \text { grife } & \text { gripe } & \text { grite }\end{array}$




$\begin{array}{llll}25) & \text { whisky } & \text { disque } & \text { risque } \\ 26) & \text { tampa } & \text { tanga } & \text { tanta } \\ 27) & \text { bica } & \text { dica } & \text { mica } \\ 28) & \text { canta } & \text { cana } & \text { cama } \\ 29) & \text { luva } & \text { uiva } & \text { ruiva } \\ 30) & \text { maca } & \text { mapa } & \text { mata } \\ 31) & \text { som } & \text { dom } & \text { bom } \\ 32) & \text { seta } & \text { neta } & \text { meta } \\ 33) & \text { gairra } & \text { jarra } & \text { barra } \\ 34) & \text { dumbo } & \text { jumbo } & \text { bumbo } \\ 35) & \text { luta } & \text { juta } & \text { guta } \\ 36) & \text { jurar } & \text { durar } & \text { furar } \\ 37) & \text { muito } & \text { mundo } & \text { minto } \\ 38) & \text { caco } & \text { calo } & \text { cato } \\ 39) & \text { risco } & \text { disco } & \text { fisco } \\ 40) & \text { agora } & \text { afora } & \text { adora } \\ 41) & \text { cua } & \text { tua } & \text { pua } \\ 42) & \text { juno } & \text { junho } & \text { julho } \\ 43) & \text { caio } & \text { caro } & \text { caco } \\ 44) & \text { terra } & \text { berra } & \text { guerra } \\ 45) & \text { afro } & \text { abro } & \text { agro } \\ 46) & \text { alar } & \text { assar } & \text { achar } \\ 47) & \text { com } & \text { cal } & \text { cão } \\ 48) & \text { mal } & \text { má } & \text { mão } \\ 49) & \text { sim } & \text { sem } & \text { se } \\ 50) & \text { cinto } & \text { cio } & \text { cito }\end{array}$

\section{Referências}

[1] "STDMG STD BUS Specification and Practice", Pro-Log Company, Documento no.10689E, Outubro 1984.

[2] L. R. Rabiner e R. W. Schafer, "Digital Processing of Speech Signals", Pentice-Hall, 1978.

[3] B. Gold e L. R. Rabiner, "Parallel Processing Techniques for Estimating Pitch Periods of Speech in the Time Domain", The Journal of the Acoustical Society of America, vol. 46, Agosto 1969, pp. 442-448.

[4] F. A. G. Ferreira, "Implementação de um Algoritmo para Extração de "Pitch" em Sinais de Voz", Tese de Mestrado, Universidade de Brasília, Departamento de Engenharia Elétrica, Dezembro 1985. 
[5] S. D. Markel e A. H. Gray, "A linear Prediction Vocoder Simulation Based Upon the Auto-Correlation Method", IEEE Transactions on Acoustics and Speech Signal Processing, vol. ASSP-22, Abril 1974, pp.124-134.

[6] B. Cold, "Note on Buzz-Hiss Detection", The doumal of the Acoustical Society of America, vol. 36, no. 9, Setembro 1964, pp.1659-1661.

[7] "TMS5220 Voice Synthesis Processor Data Manual". Texas Instruments, Junho 1981.

[8] G. Fairbanks, "Test of Phonemic Differentiation: The Rhyme Test", The Journal of the Acoustical Society of America, vol. 30, 1958, pp.596-600.

[0] G. A. Miller, G. A. Heise e W. Lichten, "The Intelligibility of Speech as a Function of the Context of the Test Materials", Jounal of Experimental Psychology, vol. 41, 1951, pp.329-335.

[10] W. D. Voiers, "Evaluating Processed Speech Using the Diagnostic Rhyme Test", Speech Technology, Janeiro/Fevereiro 1983.

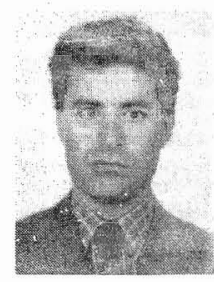

MARCO ANTONIO T. PFREIRA concluiu O curso de Engenharia Elétrica na Universidade de Brasillia em junho de 1979 e obteve - grau de Mestre em Engenharia Elétrica na Syracuse University om setembro de 1983. Fntre 1979 e 1981 e entre 1983 1985, trabalhou na equipe de desenvolvimento da Coencisa Industria de Comunicaçōes S.A. Atualmente, é sócio-gerente da Kernel Informática Lída, Brasília,DF. Suas áreas de interesse são procossamento digital de sinais, comunicação de dados, arquitetura de microprocessadores.

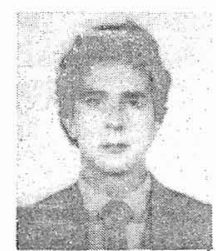

PERNANDO ACATAUASSU G. FERPEIRA concluiu o curso de Engenharia Elétrica na Universidade de Brasilla (UnB) em dezembro de 1977. Cursou pós-graduação em Eletrônica Digital na PUC-Rio e especializaçăo em Controle de Processos na UnB. Obteve o grau de Mestre em Engenharia Elétrica pela UnB on dezembro de 1985. Entre 1978 e 1985 trabalhou na equipe de desenvolvimento da Coencisa Indústria de Comunicaçoes S.A. Atualmente é sócio-gerente da Kernel Informática Lida. Brasilia, DF. Suas áreas de interesse são processamento digital de sinais, comunicações de dados, redes de comunicações. 